\title{
Roles of expectancy on employee engagement and Job performance
}

\author{
Nucharee Supatn ${ }^{1}$, Teeradej Puapradit ${ }^{2 *}$ \\ 1, 2 Assumption University, Samut Prakan, Thailand
}

\section{Keywords \\ Vroom expectancy theory Employee engagement \\ Job performance}

Received: 7 November 2018

Accepted: 6 February 2019

Published: 24 April 2019

\begin{abstract}
Employee's performance is agreed to be one of the important factors that can indicate the firm's performance. Several management and psychological factors have been focused in the researches as the factors influencing job performance of the employees. Motivation is one of the most interesting factors that could influence employee's attitudes and behaviors. This study emphasizes on Vroom's expectancy theory which explains the motivation process from effort to performance and outcomes. The study aims to examine the valid factors affecting employee engagement and job performance in respect to expectancy model. Five motivational factors modified from the original expectancy model, i.e. expectancy, extrinsic instrumentality, intrinsic instrumentality, extrinsic valence and intrinsic valence, were focused as the factors that influence employee's employee engagement and job performance. The survey was performed to collect data from 356 employees working in the firms from various sectors in Thailand. Structural Equation Modeling (SEM) was performed to analyze the data. The results indicate the direct influences of expectancy, extrinsic instrumentality, and intrinsic valence on employee engagement and indirect influence of the three factors on job performance while the influence of intrinsic instrumentality and extrinsic valence on employee engagement was not found. In addition, the direct influences of all expectancy-related constructs on job performance were not illustrated.
\end{abstract}

(C) 2019 The Author(s). Published by TAF Publishing.

\section{INTRODUCTION}

It is extensively agreed that employee's performance can account for overall organizational performance which all firms ultimately aim to maximize it. The attempts to investigate and identify factors that influence the individual performance have been rigorously done continuously. One of the psychological factors that gains most interest from researchers is motivation. A number of motivational theories from diverse viewpoints have been introduced to explain employee's attitudes and behaviors in respect to their performance. This includes the process theories of motivation since most of the theories in this group are associated with decision-making process that indicate individual's level of motivation and productivity.

Vroom's expectancy motivational theory has been, commonly, adopted to examine employee's motivation in the workplace. The expectancy theory gains recognition as one of the most accepted process theories among several under industrial and organizational psychology disciplines. Vroom (1964) devoted to clarifying the process of motivation where individuals make decision on behavioral alternatives and they are directed towards a specific course of action by motivational force. The model of this expectancy theory works on the basis of three perceptions namely: expectancy, instrumentality and valence.

Although the theory gives general insight on employee's attitude and behavior towards decision-making and motivation, the absence of the sufficient study on the relationships of the components of the model with work-related variables such as job satisfaction, employee engagement, commitment, as well as the work-related performance are still in concern. There are not many recent studies focusing on the expectancy model in respects to performance-related indicators. Most of the supporting studies were conducted

*corresponding author: Teeradej Puapradit

†email: teeradejppr@msme.au.edu 
in 1970s. Such absence prompts questioning of pragmatic approach of the theoretical model.

In the meantime, employee engagement is treated as the predictor of job performance in several studies. Employee engagement is defined as the work-related state that is active and positive with the sense of significance and enthusiasm. It seems to be a better predictor for the work performance than the job satisfaction, work flow and other jobrelated attitudes since it is not passive like job satisfaction, not just a peak episode of feeling, and also involves with both cognition and affection of the employees. Thus, the question on how the expectancy model of motivation affects employee engagement and job performance of the employees is interesting.

A. Bakker, Gierveld, and Van Rijswijk (2006), studied inrole and extra-role performance and found that they are associated with the work engagement of the employees. Schaufeli, Bakker, and Salanova (2006) also suggested the positive effect of employee engagement on in-role performance. Gierveld and Bakker (2005) reported the different level of in-role and extra-role performance between engaged and non-engaged secretaries. Thus, the relationship between employee engagement and work performance was indicated in the prvious reseraches. However, the relationship between three expectancy components of Vroom's theory and employee engagement is still in question.

Several research studies postulated job resourced and personal resources as the drivers of employee engagement (Albrecht, 2010; Chong \& Lee, 2017; Kurniawati \& MeilianaIntani, 2016; Yaemjamuang, 2017). A. B. Bakker and Schaufeli (2008) further explained the motivational roles of both factors. Job resources, such as physical, social, or organizational aspects of the job, can induce the intrinsic motivation because they encourage employees to grow, develop and learn. However, they can, also, motivate employees extrinsically when resourceful environments are instrumental to invest efforts and abilities to work and success. Therefore, the relationships between motivational effect of expectancy theory and employee engagement can be inferred. Accordingly, this study intends to examine the effects of the components in expectancy model (expectancy, extrinsic instrumentality, intrinsic instrumentality, extrinsic valence and intrinsic valence) on two work-related criteria which are employee engagement and job performance of employees from various sectors in Thailand. The results can bridge the gap between expectancy theory and work-related criterion variables that lacks recent studies to support.

\section{Objectives of the Study}

In an attempt to answer the question, "How would the expectancy constructs explain the work engagement of the employees and their job performance, the three objectives are set as follows:

1) To identify the influence of the expectancy components i.e., valence, instrumentality and expectancy on employee engagement.

2) To identify the direct and indirect influence of the expectancy components i.e., valence, instrumentality and expectancy on employees' job performance.

3) To identify the relationship between employee engagement and their job performance.

\section{Significance of the Study}

This study essentially contributes to the understanding of motivational process and allows managers or employers to be aware of the employees' needs and wants. The focus of the process of motivation, not just the motivators would promote understanding on the linkages of the organizational rewards and employees' decisions to put their effeort to perform the desirable behaviors for the organization. The research findings would enable the managerial people to develop some strategies to promote employees' motivation and engagement. Effective implementation of motivational development program would eventually result in increasing employee performance and overall organizational effectiveness.

\section{Scope of the Study}

Survey research is designed. Full time employees working in manufacturing and Fast Moving Consumer Goods (FMCG), finance and banking, business consulting and education, construction and real estate, logistics and transportation and service firms are targeted as the population of the study. A "Motivation Survey" questionnaire is developed and used as the major data collection tool to measure expectancy components, employee engagement, and job performance. The relationship among all focal constructs are examined.

\section{LITERATURE REVIEW}

\section{Expectancy Theory}

Vroom (1964) proposed the expectancy model to explain motivation by emphasizing on the the process that the employees going through to make a choice among alternative behaviors and to what extent they expend efforts on the chosen behavior. The model was developed based on the assumption that employees are pleasure seekers, rational and able to cautiously process information about their jobs, abil- 
ities and outcomes. Three major factors determining the individual motivational force are expectancy, instrumentality and valence. Expectancy is the individual's belief that one's effort will lead to certain level of performance. Employees do not exert effort to the task unless they think they can do it. Expectancy can be affected by self-efficacy, goal difficulty and perceived control on the working situation. Instrumentality is the belief that the certain level of performance will lead to the attainment of a desired outcome. Such belief can be affected by trust, control and policies. Valence is defined as desirability, importance, and attractiveness the employees place on the outcome. The instances of work-related valence are pay, job security, promotion, and opportunity to do interesting work (Ameer, 2017; Chiang \& Jang, 2008).

George and Jones (2012) elaborated that under the expectancy theory, employees become motivated when all three conditions are met. In case the expectancy is high; instrumentality is high; and valence is high, motivation would be high. Thus, motivation is illustrated if the employee says "yes" to the question, "Does he/she believe his/her input will result in a given level of performance?" and "Does he/she believe such level of performance will allow him/her to obtain the desired outcomes?" Expectancy theory is frequently employed to explain employees' motivation in organization and workplace. The explanation is on the decision making process i.e., how an individual forms motivation and becomes driven by motivators, not only identifying what the motivators are (Chiang \& Jang, 2008).

Apart from the original Vroom's expectancy model, the desirability of the outcome-valence-can be elaborated by the two types of outcomes i.e., intrinsic and extrinsic aspect as suggested by Campbell, Dunnette, Lawler, and Weick (1970). Intrinsic outcomes are internal and personal rewards, such as sense of accomplishment and self-esteem. It is considered more powerful than the extrinsic because individuals perceive the outcomes are self-administered. Extrinsic outcomes are rewards which are distributed by external agents such as manager, supervisor, and organization. They are, for example, monetary rewards, promotion, raise, new office and so on. The notion of intrinsic and extrinsic aspect is applied as well to instrumentality because both constructs are associated with the outcomes. Therefore, dividing the instrumentality and valence into internal and external aspects are justified (Chiang \& Jang, 2008). As such, the intrinsic and extrinsic valence as well as intrinsic and extrinsic instrumentality together with the expectancy are emphasized as the expectancy elements in this study. The prominent uses of expectancy theory lie in assessing, interpreting, and evaluating employee behavior in motivation (Chen \& Lou, 2002). However, there are only a small number of studies devoted to examining such areas with work-related variables. For example, Van Eerde and Thierry (1996) examined the relationship between the expectancy model and five working criterion variables i.e., performance, effort, intention, preference, and choice and found average correlations between them. Nonetheless, there is the lack of up-to-date and evident studies investigating relationship of expectancy theory and work-related criteria. Thus, the effects of five elaborated elements of expectancy model, i.e. intrinsic and extrinsic valence, intrinsic and extrinsic instrumentality and expectancy on employee job performance is proposed.

\section{Employee Engagement}

Employee work engagement refers to the work-related attitude that provides active and positive energy and influences employees to devote themselves, physically and mentally, to their job and organizations (Kahn, 1990; Eldor \& Vigoda-Gadot, 2017). Employee work engagement covers all of physical, cognitive, and emotional dimensions of the employees. Previous studies suggested that employee engagement could help enhancing employees' productivity, organizational performance, and overall business success (Putra, Cho, \& Liu, 2017; Society of Human Resource Management, 2016).

Subsequently, Schaufeli, Salanova, González-Romá, and Bakker (2002) further defined employee work engagement as a positive work-related state of mind which characterized with vigor, dedication, and absorption. The state was relatively long-lasting, pervasive and not associated with a particular event or task. Vigor refers to the state of being energetic and mentally resilient. Individuals with high vigor are willing to work hard, persistent and preserving to overcome difficulty at work. Dedication refers to sense of enthusiasm and pride of one's work. Highly dedicated employees perceive the work meaningful, challenging and inspiring. Absorption refers to the feeling of being happily engrossed and immersed in one's work. Individuals with high absorption fully concentrate in their work and detach from surroundings and time (Schaufeli \& Bakker, 2004). Schaufeli and Bakker's definition of employee engagement gained major acceptance and were adopted in various industries and researches to measure employee engagement (Putra et al., 2017).

The recent study conducted by Society for Human Resource Management or Society of Human Resource Management (2016) explained the impact of employees' perception of colleagues on employee engagement. Under this notion, en- 
gagement behavior was identified as collective actions that leads to positive outcomes of the organization, rather than that of individual employee. The results revealed that employees' perceptions on their colleagues' actions and behaviors influence their own level of employee engagement. The aspect of engagement opinion developed by Society of Human Resource Management (2016) were found to be aligned with the characteristics of vigor, dedication and absorption mentioned above.

Concepts of intrinsic and extrinsic job resource elements are commonly studied as the antecedents of employee engagement. A number of studies demonstrated relationships of intrinsic job resources with employee engagement. Supervisor support, innovativeness, and appreciation were found to have positive impact on employee engagement (A. B. Bakker, Hakanen, Demerouti, \& Xanthopoulou, 2007; Na Ayutthaya, Tuntivivat, \& Prasertsin, 2016), whereas autonomy, social support, and learning opportunities were positively related to with employee engagement (A. B. Bakker \& Bal, 2010). Coworkers' support was also found to have positive influence on vigor and dedication, but not absorption in employees working in a hospitality industry (Karatepe, Keshavarz, \& Nejati, 2010; Marfa, Niguidula, \& Enriquez, 2017).

Extrinsic job resources were not addressed with employee engagement as many as the intrinsic counterpart. Zeng, Zhou, and Han (2009) indicated that a higher pay can increase employees employee engagement. On the other hand, (Putra et al., 2017) reviewed remarked findings from Centers and Bugental (1966) and stated that there is a distinct difference between job motivators of the two work groups, white-collar and blue-collar workers. The motivation of white-collar workers were affected more by intrinsic motivators such as interesting work and satisfaction. Meanwhile, blue-collar workers were found to have more influences by extrinsic motivators such as pay and job security. Even though several work motivaors were found to have effects on employee engagement, there were no evidences that the motivatiors from the expectancy model could affect employee engagement. Thus, the hypothesis emphasizing on the effects of five expectancy elements on the employee engagement is proposed in this study.

\section{Job Performance}

Job performance has been extensively in the interest of practitioners and researchers for many decades. The recent trend of performance appraisal lies on skill and competence area, instead of a specific aspect of job. Further, the awareness of the flaws in traditional appraisal measure, which emphasize only a job itself and omitted other factors potentially contributing to overall performance, fostered considering adding non-job-related behaviors in the job performance measurement. The competency model of job performance was developed around job attributes and designed based on essential traits and abilities that employees require to do their job effectively (Welbourne, Johnson, \& Erez, 1998).

The role-based performance scale was subsequently developed based on the concept of multidimensional models of performance that comprised of job and non-job dimensions. Specifically, they are the roles of job, career, innovator, team member, and organization citizen. Two essential theories influencing development of the scale are role theory and identity theory. Role theory is used to justify the multidimensional model of job performance - suggesting that employees perform multiple roles at work - while identity theory provides guidance which roles should be included in the job performance model through compensation systems that firms reward employees who perform important roles for organizational success (Welbourne et al., 1998).

Job role represents the view of employee performance or task performance. Rotundo and Sackett (2002) extended definition of task performance from Colquitt, Lepine, Wesson, and Gellatly (2011) to work quantity and quality, job skills, and job knowledge. Similarly, Renn and Fedor (2001) explained that task performance is composed of work quantity and quality. Organization citizen role is non-job components of performance, which is also known as contextual performance. The term is defined as "behavior that supports the organizational, social, and psychological environment in which the technical core must function" (Borman \& Motowidlo, 1993). Colquitt et al. (2011) described it as voluntary activities employees perform that may or may not be rewarded but contributing to overall positive outcomes in the workplace.

Career role is considered important because firms implement promotion systems to reward individuals for career accomplishment, as well as when participating in training or acquiring new skills. Team member role was found to be essential to organizational performance and it is incorporated in many studies in the related fields of organizational behavior (Borman \& Motowidlo, 1993). Organization also promotes team member role through teambased compensation schemes - gainsharing plans and teambased incentives. Innovator role is promoted in organizations regardless of the scale of their operation. It ensures the effectiveness and adaptability of the organization to the rapid changing and dynamic business environment. Com- 
pensation schemes that firms employ to promote the innovator roles are cash rewards for constructive suggestions and promotion to those with entrepreneurial characteristics (Welbourne et al., 1998).

One of the extensively known drivers of job performance is employee engagement. Positive relationship between employee engagement and work performance were consistently found in previous research studies e.g., (A. Bakker et al., 2006; Gierveld \& Bakker, 2005; Schaufeli et al., 2006). Hence, to get the confirmation, hypothesis emphasizing on the relationship between employee engagement and work performance in employees is proposed. All three hypothe- ses were listed below while the proposed rerserach framework is presented in Figure 1.

\section{Hypothesses of the Study}

H1: Expectancy, extrinsic instrumentality, intrinsic instrumentality, extrinsic valence and intrinsic valence affect employee work engagement.

H2: Expectancy, extrinsic instrumentality, intrinsic instrumentality, extrinsic valence and intrinsic valence affect employee job performance.

H3: Employee engagement has a positive effect on employee job performance.

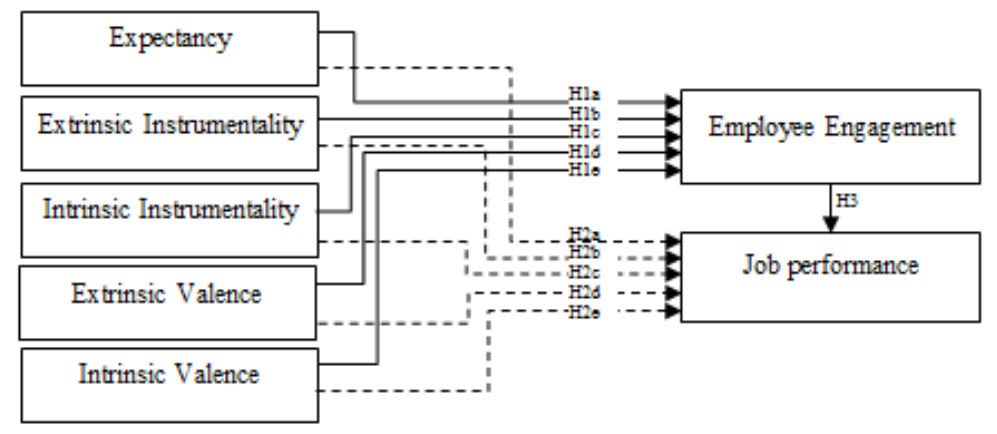

FIGURE 1. Research framework

\section{RESEARCH METHODOLOGY Population and Sample}

Target populations of the study were full time employees working in any firms. The industries were not specific since the main aim of the study was to examine the effects of expectancy elemets on employee engagement and performance of the employees in general. Nonetheless, six industries, i.e., manufacturing and FMCG, finance and banking, business consulting and education, construction and real estate, logistics and transportation and service firms, were emphasized to control of the possible effects of the business background. Convenience sampling was adopted. The sample size was determined based on the formula; $n=Z^{2} p q / E^{2}$ as proposed by Zikmund, Carr, Babin, and Griffin (2013) in which " $p$ " refers to the proportion of suxxess while " $q$ " refers to the proportion of failure. With the $p=q=0.5$ where the $95 \%$ level of confident $(Z=1.96)$ and the accepted error $(E)$ of $5 \%$ were appointed, the sample size of 385 was obtained $\left[n=(1.96)^{2 *} .05^{*} .05 /(.05)^{2}=384.16 \approx 385\right]$. "Motivation Survey" questionnaire was used as the major data collection tool. The in-person drop off technique was applied. The questionnaires were handed in to the employees who agreed to join the survey. The data collections were done on the voluntary basis. Four hundred sets of data were ontained. However, 44 sets of the them were found incomplete. Thus, they were discarded from the analysis. ThereISSN: 2414-309X

DOI: $10.20474 /$ jabs-5.2.3 fore, a total of 356 data sets were used for the data analysis. This yielded $89 \%$ of the response rate. The sample profiles are illustrated in Table 1.

Out of this, 56.7 percent were female and the rest 43.3 were male in which $41.6 \%$ were $30-45$ years old followed by those who were less than 30 years old, $40-60$ years old and more than 60 years old with $30.9 \%, 27.0 \%$ and $0.6 \%$, respectively. For the education, 53.4\% held bachelor's degree, followed by $26.4 \%$ got below bachelor's and the rest $20.2 \%$ had above bachelor's degree. Most of them worked in Manufacturing and FMCG firms (23.6\%), followed by finance and banking (20.5\%), business consulting and education $(20.2 \%)$, construction and real estate $(14.1 \%)$, hospitality and other related service firms (12.9\%) and logistics and transportation (8.7\%). A total of 73.2 percent worked as the officers or operating positions while the rest 26.8 Percent held the managerial positions, i.e., supervisors, managers, directors and CEO. In addition, the firms that they work for are mostly private companies (31.5\%), public companies (26.7\%), international/joint venture companies (17.6\%) and the rest 24.2 percent worked in other types of the companies. Most of the firms are small sized with less than 100 employees (43.9\%), followed by large sized with more than 500 employees (33.2\%) and medium sized with 100-500 employees (22.7\%), respectively. 
TABLE 1. Sample profiles and firm's characteristics

\begin{tabular}{lll}
\hline \hline & Sample Characteristics & Percent \\
\hline Industry & Manufacturing/FMCG & 23.6 \\
& Finance and Banking & 20.5 \\
& Business Consultancy and Education & 20.2 \\
& Construction/Real Estate & 14.1 \\
& Hospitality and other related services & 12.9 \\
& Logistics and Transportation & 8.7 \\
Firm Types & Private & 31.5 \\
& Public & 26.7 \\
Firm Size & international/joint venture & 17.6 \\
(Number of employees) & Others & 24.2 \\
& Less than 100 employees & 43.9 \\
Gender & More than 500 employees & 22.7 \\
Age & Male & 33.2 \\
& Female & 56.7 \\
& Less than 30 years old & 43.3 \\
& 30-45 years old & 30.9 \\
Education & 45-60 years old & 41.6 \\
& More than 60 years old & 27.0 \\
Working Position & Below Bachelor's & 0.6 \\
& Bachelor's & 26.4 \\
\hline \hline & Above Bachelor's & 53.4 \\
& Operating & 20.2 \\
& Managerial (Supervisors, managers, directors and CE0) & 73.2 \\
& & 26.8 \\
\hline
\end{tabular}

\section{Measurement and Pre-Test}

The measurements of the employee's expectancy were modified from Chiang and Jang (2008) in which the three expectancy components of Vroom i.e., expectancy, instrumentality and valence were elaborated to five dimensions which were expectancy, intrinsic instrumentality, extrinsic instrumentality, intrinsic valence, and extrinsic valence. A total of 16 measurement items were used. First four items measured expectancy, next four items measured extrinsic instrumentality, and the rest two, three and last tree items measured intrinsic instrumentality, extrinsic valence, and intrinsic valence. The five-point rating scales were designed. Likert scales varying from 1 (strongly disagree) to 5 (strongly agree) were applied. The measurements of employee engagement were modified from the study of the Society for Human Resource Management (SHRM) in 2016. Two dimensions of engagement i.e., engagement behavior and engagement opinion were measured by 8 and 11 items, respectively.

The same Likert scales varying from 1 (strongly disagree) to 5 (strongly agree) were used. The role-based performance Scale modified from the study of Welbourne et al.
(1998) was used. Twenty measurement items were used to measure five dimensions of job performance which are job, career, innovator, team-working, and organization.

TABLE 2. Reliability test results of the pre-testing of the questionnaire

\begin{tabular}{lll}
\hline \hline Constructs & Cronbach's Alpha & $\begin{array}{l}\text { Number } \\
\text { Questions }\end{array}$ \\
\hline Expectancy & 0.871 & 4 \\
Extrinsic Instrumentality & 0.902 & 4 \\
Intrinsic Instrumentality & 0.766 & 2 \\
Extrinsic Valence & 0.814 & 3 \\
Intrinsic Valence & 0.814 & 3 \\
Employee Engagement & 0.928 & 19 \\
Engagement Behavior & 0.822 & 11 \\
Engagement Opinion & 0.837 & 8 \\
Job performance & 0.945 & 20 \\
Job & 0.892 & 4 \\
Career & 0.837 & 4 \\
Innovator & 0.892 & 4 \\
Teamwork & 0.874 & 4 \\
Organization & 0.880 & 4 \\
\hline \hline
\end{tabular}

To ensure that the measurements were reliable, the Cronbach's alpha co-efficient and item-to-total analyses were 
performed. The questionnaires were distributed to fourtyfive employees of a firm by the HR manager. The Cronbach's alpha coefficients of 0.766 to 0.945 were obtained (See Table 2). All of the coefficients exceeded the cutoff point of 0.7 as mentioned by Nunnally (1978). The internal consistency of the measurements was ensured. Thus, the questionnaire was said to be reliable and can be used as the major tool for the data collection.

\section{Confirmatory Factor Analysis (CFA)}

SEM was applied to test research framework and structural relations of the main constructs. CFA was firstly done to verify the construct validity of the measurements. Satisfactory results were obtained. Fitted CFA model was illustrated since all fit indices were in the required level, i.e., chi-square per degree of freedom $(\lambda 2 / d f)$ was 1.82 which exceeded the recommended point of $<3.0$; Other relative fit indices were in the required range of more than 0.90 but less than 1.00 (IFI = 0.913; TLI $=0.904 ; \mathrm{CFI}=0.912$ ) and the RMSEA was 0.048 which was less than the cutoff point of 0.08 . Thus, the validity of the measurement model was ensured.

\section{SEM}

SEM was developed. Five dimensions of expectancy constructs were appointed as independent variables while the second order construct of the employee engagement and job performance were appointed as the intervening and dependent variables, respectively. Two first-order constructs of the engagement, engagement opinion and engagement behavior, and five first-order constructs of the job performance, job, career, innovator, team-working, and organization, were used. Figure 2 shows the structural relations of the main constructs of the study.

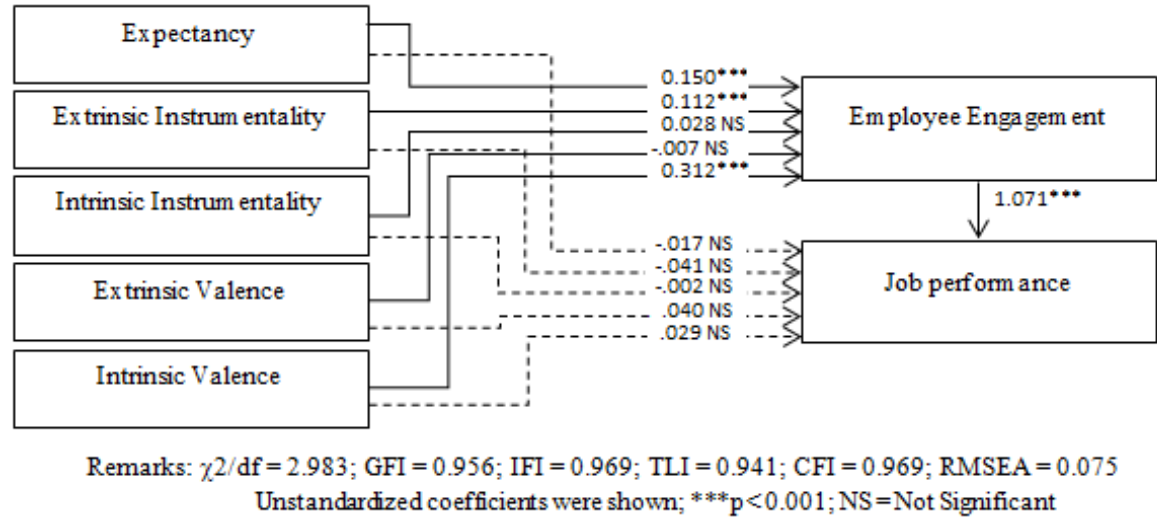

FIGURE 2. Structural relations among the main constructs

As the fits of the structural equation model was illustrated $(\lambda 2 / d f=2.983 ; \mathrm{GFI}=0.956 ; \mathrm{IFI}=0.969 ; \mathrm{TLI}=0.941 ; \mathrm{CFI}=$ 0.969; RMSEA $=0.075$ ), Structural relationship among the main constructs can be identified as seen in Figure 2. Significant relationship between expectancy, extrinsic instrumentality, and intrinsic valence and employee engagement were shown while significant relationship of the intrinsic instrumentality and extrinsic valence and employee engagement were not seen. Significant relationship between expectancy constructs and job performance were also not illustrate. As Hypotehsis 1 proposed the effects of five expectancy constructs on employee engagement, significant effects of expectancy $(\beta=0.150 ; p<0.001)$, extrinsic instrumentality $(\beta=0.112 ; p<0.001)$, and intrinsic valence ( $\beta=0.312 ; p<0.001$ ) on employee engagement were found while those of intrinsic instrumentality $(\beta=0.028 ; p>0.05)$ and extrinsic valence $(\beta=-0.007 ; p>0.05)$ were not found. Thus, H1 was partially supported by the data. Hypothe- sis 2 was not supported by the data since significance effects of all expectancy constructs on job performance were not found $(\beta=-0.017,-0.041,-0.002,0.040$, and $0.029 ; p$ $>0.05$ ). The positive and significant effect of employee engagement on job performance was shown $(\beta=1.071 ; p<$ 0.001). As such, Hypothesis 3 was fully supported by the data. Hence, Hypothesis 1 was partially supported by the data while Hypothesis 2 was not and Hypothesis 3 was supported by the data. The details can be seen in Table 3. Regarding the hypothesis testing results, direct effects of expectancy, extrinsic instrumentality and intrinsic valence on employee engagement and indirect effects of the three constructs on job performance via employee engagement were shown. Direct influences of all expectancy constructs on job performance were not found. In addition, extrinsic valence and intrinsic instrumentality had no effects on both employee engagement and job performance. 
TABLE 3. Path analysis results

\begin{tabular}{lll}
\hline \hline Structural Relation & $\beta(\mathbf{S t d} \beta)$ & C.R. $(\boldsymbol{p}$-value) \\
\hline Expectancy $\rightarrow$ Engagement & $0.150(0.258)$ & $4.366^{* * *}$ \\
Extrinsic Instrumentality $\rightarrow$ Engagement & $0.112(0.204)$ & $3.391^{* * *}$ \\
Intrinsic Instrumentality $\rightarrow$ Engagement & $0.028(0.040)$ & $.699(\mathrm{NS})$ \\
Extrinsic Valence $\rightarrow$ Engagement & $-0.007(-0.011)$ & $-.197(\mathrm{NS})$ \\
Intrinsic Valence $\rightarrow$ Engagement & $0.312(0.408)$ & $6.959^{* * *}$ \\
Expectancy $\rightarrow$ Performance & $-0.017(-0.026)$ & $-.527(\mathrm{NS})$ \\
Extrinsic Instrumentality $\rightarrow$ Performance & $-0.041(-0.066)$ & $-1.348(\mathrm{NS})$ \\
Intrinsic Instrumentality $\rightarrow$ Performance & $-0.002(-0.002)$ & $-.050(\mathrm{NS})$ \\
Extrinsic Valence $\rightarrow$ Performance & $0.040(0.052)$ & $1.239(\mathrm{NS})$ \\
Intrinsic Valence $\rightarrow$ Performance & $0.029(0.034)$ & $.624(\mathrm{NS})$ \\
Engagement $\rightarrow$ Performance & $1.071(0.956)$ & $9.835^{* * *}$ \\
\hline \hline
\end{tabular}

Remarks: Unstandardized Coefficients (b) are shown; standardized coefficients are shown in the brackets; C.R. = Critical Ratio

\section{DISCUSSION}

The findings indicates the indirect effects of the three expectancy constructs, i.e., expectancy, extrinsic instrumentality, and intrinsic valence as proposed by Chiang and Jang (2008) on employee engagement and indirect effects on the work performance. These findings suggest that the employees become actively engaged with their job when they think that they would receive what they want if they put full effort and successfully perform the required jobs. Taking responsibility, utilizing their own skills and accomplishments are important for employees to accomplish their jobs. Engaged employees are confident to do their job well, have perseverance and take mentally and physically active role to do the assigned work. In other words, they are characterized with vigor, dedication and absorption at work. Employee engagement, in turn, affects work performance on the dimensions of job, career, innovator, team-working, and organization, which they all come down to efficiency and effectiveness of the organization. Nonetheless, the direct relationship between the constructs of expectancy theory and work performance do not exist. Job performance does not increase nor decrease without the feeling of employee engagement.

The relationship between intrinsic outcomes and job performance is consistent with the findings from Mitchell and Albright (1972) where the intrinsic variable was reported to have greater predictive effect than those of extrinsic counterparts. The findings from the current study also consistent with the research results of Chiang and Jang (2008) in that the intrinsic rewards, such as a sense of accomplishment or positive feeling about their jobs, are more influential to motivate employees than extrinsic ones such as pay raise, bonuses, promotions. Moreover, A. B. Bakker and
Schaufeli (2008) and A. B. Bakker (2011) reported the consistent results that engaged employees are able to perform better because they experience the set of positive feelings at work i.e., happiness, joy and enthusiasm and they also transfer those emotions to other colleagues. Putra et al. (2017) confirmed the positive effect of intrinsic motivation on employee engagement. Meaningfulness and interestingness of job increase intrinsic motivation and eventually help employees become more engaged with work.

The findings from this current study sugget that employees with high expectancy believe their efforts are effective which would lead to a desired level of performance or productivity. Such belief also directs them to engage themselves with their work i.e. forming a positive work-related state of mind through the dimensions of engagement opinion and engagement behavior. Subsequently, their physically and mentally engaging actions would result in improving their actual work performance. Employees with high instrumentality believe that achieving the performance expectations allows them to obtain desired outcomes, especially external rewards. In other words, employees thinking of the performing well in their work help them get monetary bonuses, pay raises, promotions or other kinds of the organizational rewards.

The employees would perform better as a result of having engaging attitude and engaging behavior with their work. However, by performing well they may not believe in experiencing the intrinsic instrumentality such as sense of accomplishment or having pride of themselves. Valence has essential role in motivating the employees yet only intrinsic valence is perceived important. More control over their job, being able to fully use skills and feeling selfaccomplishment are what the employee desire to obtain. 
The desirability or attractiveness of the outcome directs the employees to involve in employee engagement and increase their work performance thereafter.

\section{CONCLUSION}

In spite of the fact that employees perceive the probability of receiving extrinsic outcomes from achieving a certain level of performance as depicted by external instrumentality, intrinsic valence is considered important aspect to get them motivated. The employees perceive feeling of achievements and feeling positive on themselves are attractive rewards but what motivates them to maintain high performance are actually extrinsic rewards. The finding could be explained with the lack of the recognition of employees on the link between performing at high level and intrinsic outcomes, such as self-fulfillment and feeling good about themselves or self-pride. The possible cause could be overemphasizing of the firm on extrinsic outcomes and failing to communicate the consequential intrinsic outcomes to the employees. Thus, the employees would become motivated to work and improve their actual work performance when expectancy, extrinsic instrumentality and intrinsic valance are secured. Additionally, employee engagement accounts for the relationship of the three constructs from modified expectancy model and work performance.

\section{IMPLICATIONS}

This study signifies and contributes to the understanding about employees on how their motivational process works. Employees are aware that their effort contributes to productivity, quality, quantity of the work and organizational goals attainment; furthermore, motivation can push them to work harder and contribute more for the organizational success. Thus, for managers to enhance job performance of the employees, expectancy, intrinsic valence and extrinsic instrumentality should be fostered. In other words, they should establish a clear mental pathway on the employees from having high performance to attaining feelings of achievement and pride of self-accomplishments. Trust of the employees on ability to obtain rewards must be built with assistance from the managers. At the same time, sufficient trainings must be provided to increase employees' competency and allow them to fully utilize their skills to increase instrumentality.

To actualize employees' extrinsic instrumentality and raise motivation, their desired intrinsic outcomes should be distributed accordingly once they are able to accomplish expected level of performance. Organizational policies and managers' control of the reward have effects on this attitude. The managers can observe the change initiated by expectancy-related constructs from employee engagement opinion and behavior of the employees which eventually affects their job performance.

The limitations lie on generalization of the results to employees in certain industries. The majorities of the data were collected from six business industries i.e. manufacturing and FMCG, financial and banking, consultancy and educational services, construction and real estate, hospitality, and logistics and transportation. Future researches may focus on other industries apart from these six. Moreover, the study of the relationship between expectancy constructs, employee engagement and job performance of the employees in each industry can be focused.

There are also potential opportunities to expand the scope of this study. Comparative study between private and public companies in the equitable proportion of sample can be considered. The investigation may suggest the difference of motivational forming process between the two groups and contribute to more pragmatic and effective implications of motivational development program for the employees. Moreover, some other variables may be put in the model to explore further possible indirect effect between the components of expectancy theory and job performance. This may enhance effectiveness and feasibility of the framework. Since employee's motivation are relatively subjective to employee's perceptions, a research should be conducted in an in-depth and ongoing manner. Such approach could help managers understand and identify underlying factors influencing employee's motivation and performance.

\section{REFERENCES}

Albrecht, S. L. (2010). Handbook of employee engagement: Perspectives, issues, research and practice. Glasgow, UK: Edward Elgar.

Ameer, N. (2017). Impact of organizational culture on employee performance and Organizational Citizenship Behavior (OCB). International Journal of Business and Administrative Studies, 3(5), 183-196. doi:https://doi.org/10.20469/ ijbas.3.10004-5

Bakker, A., Gierveld, J., \& Van Rijswijk, K. (2006). Success factors among female school principals in primary teaching: A study on burnout, work engagement, and performance. Diemen, Netherlands: Right Management Consultants. 
Bakker, A. B. (2011). An evidence-based model of work engagement. Current Directions in Psychological Science, 20(4), 265-269. doi:https://doi.org/10.1177/0963721411414534

Bakker, A. B., \& Bal, M. P. (2010). Weekly work engagement and performance: A study among starting teachers. Journal of Occupational and Organizational Psychology, 83(1), 189-206. doi:https://doi.org/10.1348/096317909x402596

Bakker, A. B., Hakanen, J. J., Demerouti, E., \& Xanthopoulou, D. (2007). Job resources boost work engagement, particularly when job demands are high. Journal of Educational Psychology, 99(2), 274-284. doi:https://doi.org/10.1037/0022 $-0663.99 .2 .274$

Bakker, A. B., \& Schaufeli, W. B. (2008). Positive organizational behavior: Engaged employees in flourishing organizations. Journal of Organizational Behavior, 29(2), 147-154. doi:https://doi.org/10.1002/job.515

Borman, W. C., \& Motowidlo, S. (1993). Expanding the criterion domain to include elements of contextual performance. San Francisco, CA: Jossey-Bass.

Campbell, J. J., Dunnette, M. D., Lawler, E. E., \& Weick, K. E. (1970). Managerial behavior, performance, and effectiveness. New York, NY: McGraw-Hill.

Centers, R., \& Bugental, D. E. (1966). Intrinsic and extrinsic job motivations among different segments of the working population. Journal of Applied Psychology, 50(3), 193-200. doi:https://doi.org/10.1037/h0023420

Chen, Y., \& Lou, H. (2002). Toward an understanding of the behavioral intention to use a groupware application. Journal of Organizational and End User Computing (JOEUC), 14(4), 1-16. doi:https://doi.org/10.4018/joeuc.2002100101

Chiang, C.-F., \& Jang, S. S. (2008). An expectancy theory model for hotel employee motivation. International Journal of Hospitality Management, 27(2), 313-322. doi:https://doi.org/10.1016/j.ijhm.2007.07.017

Chong, C. Y., \& Lee, T. S. (2017). Employee retention and job performance attributes in private institutions of higher education. International Journal of Business and Administrative Studies, 3(5), 158-165. doi:https://doi.org/10.20469/ ijbas.3.10001-5

Colquitt, J., Lepine, J. A., Wesson, M. J., \& Gellatly, I. R. (2011). Organizational behavior: Improving performance and commitment in the workplace. New York, NY: McGraw-Hill Irwin.

Eldor, L., \& Vigoda-Gadot, E. (2017). The nature of employee engagement: Rethinking the employee--organization relationship. The International Journal of Human Resource Management, 28(3), 526-552. doi:https://doi.org/10.1080/ 09585192.2016 .1180312

George, J. M., \& Jones, G. R. (2012). Understanding and managing organizational behavior. New Jersey, NJ: Pearson Education.

Gierveld, J., \& Bakker, A. (2005). De invloed van de secretaresse: The influence of the secretary. Diemen, Netherlands: Manpower.

Kahn, W. A. (1990). Psychological conditions of personal engagement and disengagement at work. Academy of Management Journal, 33(4), 692-724. doi:https://doi.org/10.5465/256287

Karatepe, O. M., Keshavarz, S., \& Nejati, S. (2010). Do core self-evaluations mediate the effect of coworker support on work engagement? A study of hotel employees in Iran. Journal of Hospitality and Tourism Management, 17(1), 62-71. doi:https://doi.org/10.1375/jhtm.17.1.62

Kurniawati, E. P., \& MeilianaIntani, A. (2016). Effect analysis of the use of accounting information, managerial performance and employee performance towards SMEs. Journal of Administrative and Business Studies, 2(3), 130-142. doi:https:// doi.org/10.20474/jabs-2.3.4

Marfa, M. A., Niguidula, J. D., \& Enriquez, J. B. (2017). Business analytics in performance assessment of food manufacturing system. International Journal of Business and Economic Affairs, 2(2), 159-164. doi:https://doi.org/10.24088/ijbea -2017-22009

Mitchell, T. R., \& Albright, D. W. (1972). Expectancy theory predictions of the satisfaction effort, performance, and retention of naval aviation officers. Organizational Behavior and Human Performance, 8(1), 1-20. doi:https://doi.org/10.1016/ 0030-5073(72)90033-5

Na Ayutthaya, J. S., Tuntivivat, S., \& Prasertsin, U. (2016). The effect of positive psychological capital and organizational climate on service quality: The mediation role of work engagement of hotel service employees in Ratchaburi province. Journal of Administrative and Business Studies, 2(4), 167-176. doi:https://doi.org/10.20474/jabs-2.4.3

Nunnally, J. (1978). Psychometric theory. Hillsdale, NJ: Mcgraw-Hill. 
Putra, E. D., Cho, S., \& Liu, J. (2017). Extrinsic and intrinsic motivation on work engagement in the hospitality industry: Test of motivation crowding theory. Tourism and Hospitality Research, 17(2), 228-241. doi:https://doi.org/10.1177/ 1467358415613393

Renn, R. W., \& Fedor, D. B. (2001). Development and field test of a feedback seeking, self-efficacy, and goal setting model of work performance. Journal of Management, 27(5), 563-583. doi:https://doi.org/10.1177/014920630102700504

Rotundo, M., \& Sackett, P. R. (2002). The relative importance of task, citizenship, and counterproductive performance to global ratings of job performance: A policy-capturing approach. Journal of Applied Psychology, 87(1), 66-77. doi: https://doi.org/10.1037//0021-9010.87.1.66

Schaufeli, W. B., \& Bakker, A. B. (2004). Job demands, job resources, and their relationship with burnout and engagement: A multi-sample study. Journal of Organizational Behavior, 25(3), 293-315. doi:https://doi.org/10.1002/job.248

Schaufeli, W. B., Bakker, A. B., \& Salanova, M. (2006). The measurement of work engagement with a short questionnaire: A cross-national study. Educational and Psychological Measurement, 66(4), 701-716. doi:https://doi.org/10.1177/ 0013164405282471

Schaufeli, W. B., Salanova, M., González-Romá, V., \& Bakker, A. B. (2002). The measurement of engagement and burnout: A two sample confirmatory factor analytic approach. Journal of Happiness Studies, 3(1), 71-92. doi:https://doi.org/ 10.1023/a:1015630930326

Society of Human Resource Management. (2016). Shrm research overview: Employee engagement. Retrieved from https : // bit.1y/2qyd9Hu (Accessed on 19 July, 2018)

Van Eerde, W., \& Thierry, H. (1996). Vroom's expectancy models and work-related criteria: A meta-analysis. Journal of Applied Psychology, 81(5), 575. doi:https://doi.org/10.1037/0021-9010.81.5.575

Vroom, V. (1964). Work and motivation. New York, NY: Wiley.

Welbourne, T. M., Johnson, D. E., \& Erez, A. (1998). The role-based performance scale: Validity analysis of a theory-based measure. Academy of Management Journal, 41(5), 540-555. doi:https://doi.org/10.2307/256941

Yaemjamuang, B. (2017). Investigating motivation of the hotel employees at the operational level: A case study of the hotel business in Samut Songkram Province, Thailand. International Journal of Business and Economic Affairs, 2(1), 8-11. doi:https://doi.org/10.24088/ijbea-2017-21002

Zeng, H., Zhou, X., \& Han, J.-l. (2009). Employee engagement and personal performance in hotel service industry of China. In 2009 6th International Conference on Service Systems and Service Management, Tokyo, Japan.

Zikmund, W. G., Carr, J. C., Babin, B., \& Griffin, M. (2013). Business research methods. New York, NY: Nelson Education. 